International Journal of Solar Thermal Vacuum Engineering

\title{
Wave energy in the UK: Current scope, challenges and prognostications
}

\author{
Saim Memon ${ }^{1 *}$, Olatunde Muisdeen Lawal ${ }^{1}$, Sumair Ahmed Tariq ${ }^{1}$, Bilal Khalid ${ }^{1}$ \\ 1 Solar Thermal Vacuum Engineering Research Group, London Centre for Energy Engineering, School of Engineering, London South Bank \\ University, London, United Kingdom
}

\section{ABSTRACT}

This paper reviews the current status, challenges and prognostications of wave energy systems (WES), which have momentous scope in the UK that could deliver the UK's net zero energy target by 2050. In Britain, there are 43 primary seaside towns around the coast in which 37 are in England that encompass a collective population of 2.9 million and signify around $5.7 \%$ of the population of England as a whole where the zero energy coastline house projects can be initiated with WES. The progress in the development of standalone WES for a vision of zero energy coastline houses is still in its initial stages. This paper exhibited a brief review of the onshore, nearshore and offshore WES technologies, particular focus was made to the scope in the UK. The feasibility and efficiency of WES study imply that the power take off (PTO) efficiency is crucially important as the overall output depends on the optimum energy harness from WES that will improve its competitive prowess with other renewable technologies and further reduce the cost of WES manufacturing. This study implicates one of prognostications that developing marine energy resources in the UK can save 60 metric tons of carbon dioxide by 2025. This study also concluded that WES can pose environmental challenges such as alterations of water column to biota and sea-bed habitats, dredging, noise and vibrations. The prognostication of zero energy coastline houses arises due to the location of the UK, which is one of the major determinants for the future success of wave energy projects, as the UK is located at the long fetch of the Atlantic Ocean and has the wind direction from the west. The available resource to harness wave energy in the UK is around $120 \mathrm{GW}$.

\section{Keywords:}

Wave energy system; onshore; nearshore; offshore; zero energy coastline houses

Copyright @ 2020 PENERBIT AKADEMIA BARU - All rights reserved

\section{Introduction}

The UK will produce and rely more on its abundant renewable energy resources which is one of the major factors of self-reliance in the post-Brexit scenario and for socio-economic stability in the UK [1]. It is perceived that wave energy systems (WES) have momentous scope in the UK that could deliver the UK's net zero energy target by 2050 [2]. Due to its calculated scope to generate 40-50 TWh/year that accounts around $15 \%$ of the present UK electrical energy demand. Wave energy, also called ocean wave energy, is another category of sea based renewable energy resource that utilizes the intensity of the water waves to produce electrical power. It is dissimilar to tidal energy, which utilizes the recurring pattern of the tides [3]. Wave energy is a rigorous type of solar energy naturally

\footnotetext{
* Corresponding author.

E-mail address: $\underline{\text { S.Memon@Isbu.ac.uk }}$
}

https://doi.org/10.37934/stve.2.1.5978 
occurred due to the sun beams strike the Earth's air, they warm it up, contrasts in the temperature of the air masses far and wide makes the air move from the more blazing districts to the cooler locations resulting in waves. As the wind contempt the outside of the seas, a segment of the wind energy is exchanged to the water beneath, producing waves. The coastal areas in the UK could be a tremendous stockpiling authority of energy conversion/ exchanged by the sun to the seas, with the waves conveying the exchanged active energy over the outside of the seas. Since seas spread in excess of 70 percent of the world's surface, they get a tremendous amount of solar energy [4]. Profound sea flows, waves, and tides all are a significance of the sun's brilliant vitality and differential warming of the world's surface and seas [5].

Wave energy has the capacity to travel for long distances with low energy loss. For instance, the wind storm originated from the "Western Atlantic Ocean" have the capacity to travel toward the "Western Cost of Europe" with a very minimal loss of the energy [6,7]. It is revealed that the wave energy systems can produce up to $90 \%$ of the global energy demand. The resource and demand correlation for wave energy is very effective. The main reason behind the effective correlation is that $37 \%$ of the world population is settled in the coastal areas [8]. At the global level, the major energyrich areas include "Northern Hemisphere $(\mathrm{NH})$ and Southern Hemisphere $(\mathrm{SH})$ ". it is calculated that the highest mean value for the wave is at $\mathrm{SH}$ and the seasonal variations are very low [9]. Although the interest of researchers and scientist in the UK have been increased toward the wave energy. The investigation on the wave energy in the UK has been started since 1970s. It is also important to consider that there are several governments funded research took place in the UK to identify the wave energy feasibility. The investigation of government role in the development of the wave energy highlight that the UK government and the EU commission have played a vital role in the development of the current status of wave energy [10].

This review paper bestows the current scope of onshore, nearshore and offshore wave energy systems, particularly in the UK with discussions on UK case study along with the prominent prototype examples around the world. This review paper contributes to the status and prognostication of wave energy systems in the UK. It discusses the feasibility and efficiency along with environmental challenges of different wave energy systems. The prognostication of zero energy coastline houses with a potential of standalone wave energy system in the UK that will play a vital role in the UK's mission of self-sustained zero carbon economy are also discussed.

\section{Overview of the principle of Wave Energy Systems (WES)}

Wave energy systems (WES) can thereby be categorised based on location, working principles, sizes and impact on environment, it can further be attributed to the water depth. WES can be prescribed as onshore, nearshore, or offshore with respect to the installation areas, as shown in Fig.1 [7]. One of the complexities in implementing WES is due to the variation in sea conditions that serves as the main force behind its high cost of implementation [11,12]. There are numerous kinds of techniques that can be used to harness wave energy and are dependent, primarily, on location and water depth. The WES devices are categorized in to six types according to their functionality that are: attenuator; point absorber; oscillating wave surge converter; oscillating water column; overtopping device and; submerged pressure differential. as shown in Fig 2. [7]. 


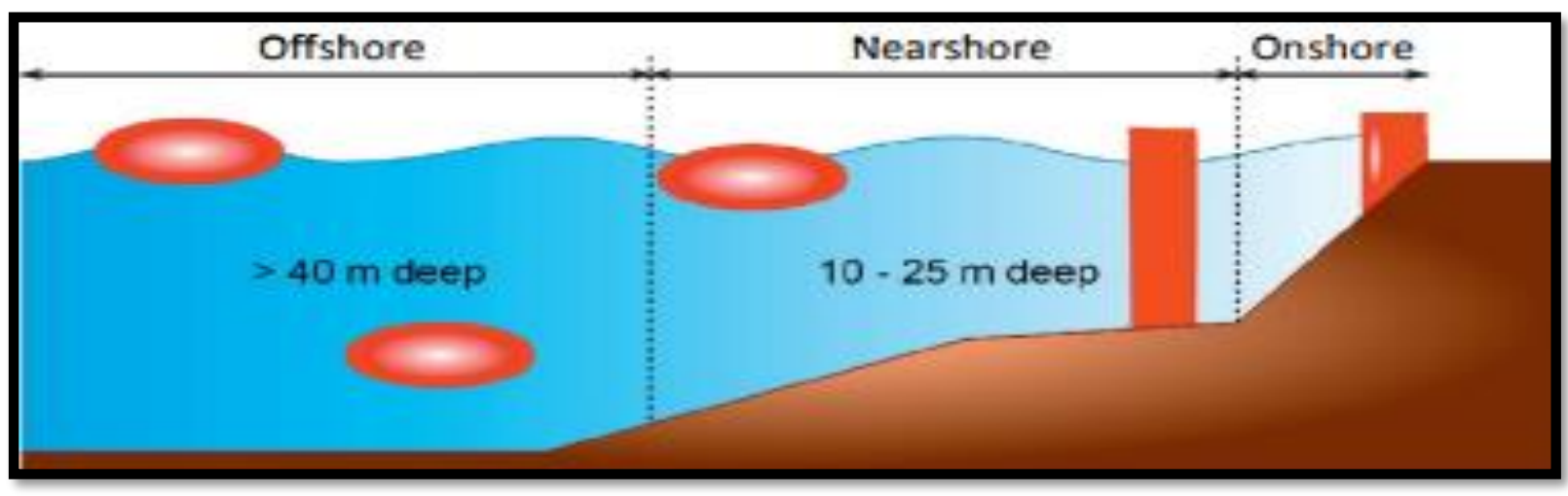

Fig. 1. Illustration of onshore, offshore and offshore categories for Wave Energy Systems (WES) [6]

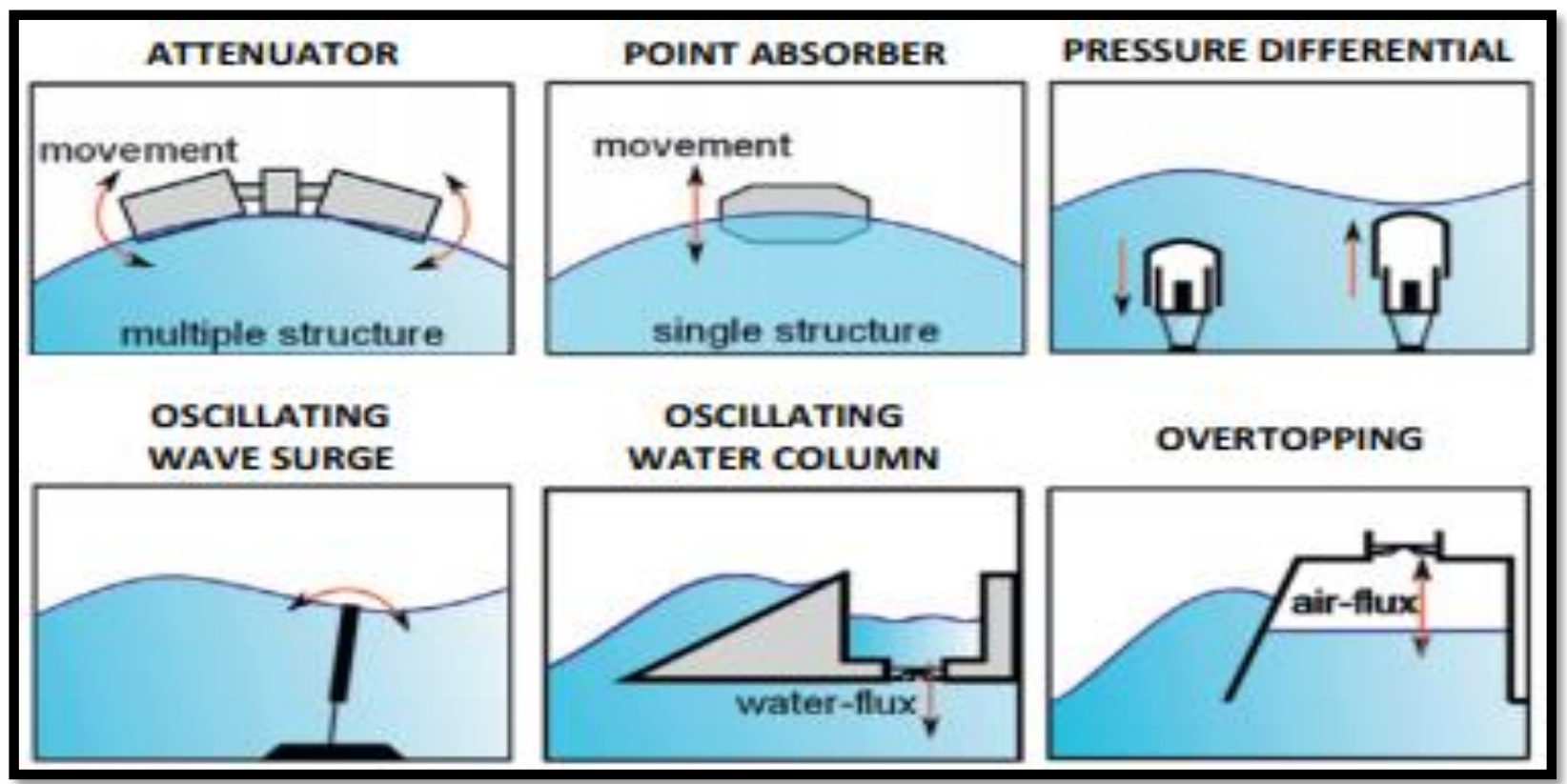

Fig. 2. Kinds of Wave Energy Systems (WES) [6]

Historically, WES rely on the following three fundamental methods of the upward and downward motion of waves that drive blades of turbine which in turn connected to an electrical generator.

- Float or buoy method rely on the upsurge and down surge of ocean swells to propel hydraulic pumps, it can be mounted to a floating raft or to a device fixed on the ocean bed. A series of anchored buoys upsurge and down surge with the ocean wave, these continuous movements are then utilised to propel the turbine of an electrical generator to generate electrical power, which is then transmitted ashore by underwater power cables [13].

- Oscillating water column (OWC) method rely on the inward and outward motion of waves at the shore that enters through a column. This column fills with water as the wave upsurges and empties as it down surges which compresses air inside the column and eventually force air to turn a turbine of an electrical generator [14]. Installation of it is normally located on the shoreline or sometimes nearshore which potentially possesses advantages in terms of easier installation, maintenance and do not require the use of long underwater electrical cables due to its location on the shoreline. Although installation of shoreline devices could 
possess a reduction in efficiency due to less energetic wave climate, slight compensation can be acquired through refraction or diffraction of natural wave energy concentration $[15,16]$. OWC control objectives lies into the categories of air flow control, rotational speed control and the maximization of output power [17]. It was identified that excess of air flow rate decreases the output power due to stalling losses to wells turbine [18]. This was established by the investigation of the relationship between the coefficient of flow, power and torque values. The investigation demonstrates mathematically that the flow coefficient is directly proportional to air flow velocity, therefore an increase in air flow velocity, will presents an increase in flow coefficient which later results into longer torque coefficient. However, the critical flow coefficient is limited, therefore continuous increase of wave input above the critical flow coefficient will cause a significant reduction in turbine efficiency, this is termed as the stalling phenomenon, similar phenomenon of the betz limit of wind turbine [18]. Implementation of air valves with OWC will enable the operation of wells turbine at maximum efficiency without any stalling behaviour. The main difference between the floating and fixed OWC is the fact that where the fixed structure devices stand still (fixed) on the sea bottom and the floating OWC can oscillate freely.

- Tapered channel method relies on a shore mounted structure to channel and concentrate the waves driving them into an elevated reservoir. Water flow out of this reservoir is used to generate electricity using standard hydropower technologies [14].

\section{Onshore Wave Energy Systems (WES)}

Onshore wave energy systems (WES) are typically located at the shore $(10 \mathrm{~m})$ and mostly embedded or fixed to shoreline itself. The maintenance and installation of onshore WES are easier as compared to offshore or nearshore WES, where long length underwater cables and deep-water mooring is not required but the waves hold quite limited power at the shoreline. The deployment of onshore WES could affect the coastal scenery and onshore geology [7]. There are a number of onshore WES currently installed all over the world and most of them are in prototype or in the testing stage. In the following subsections, Pico plant in Portugal and Limpet in the UK are briefly reviewed.

\subsection{Pico plant}

The European pilot Pico Plant installed in Lisbon; Portugal is an OWC type WES with the installation capacity of $400 \mathrm{~kW}$ as shown in Fig. 3 [10]. This plant was designed for testing purposes and to supply electricity to a small part of town on a permanent basis. It was a research and development project with 25 years of life span for its mechanical and electrical parts and it was built in small remote island with relatively high unit and start-up cost [19]. The cost of monitoring and maintenance was high as compared to traditional plants of the same capacity and many comments about actual performance and efficiency are available. 


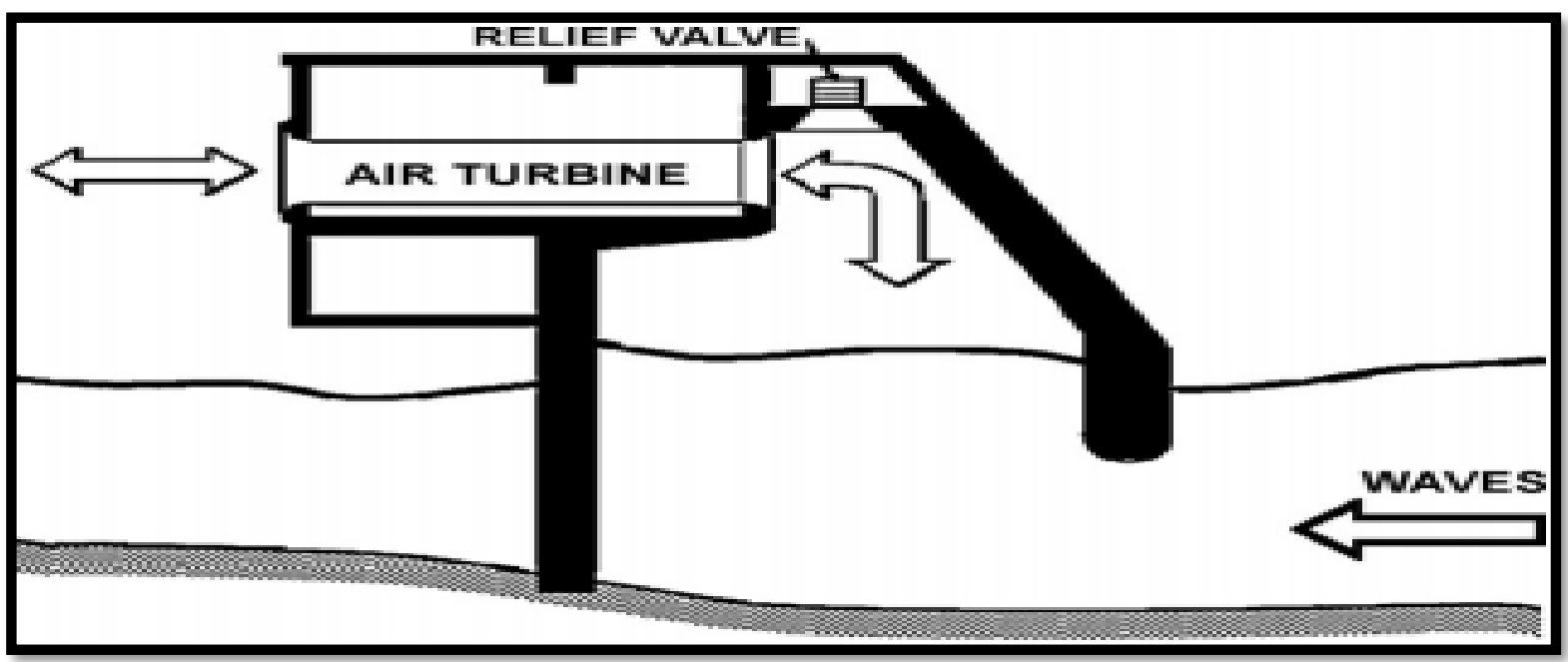

Fig. 3. A cross-sectional illustration of a bottom-standing European pilot Pico Plant installed in Lisbon, Portugal, which is an OWC type WES [10]

\subsection{The Limpet}

In the UK, the onshore WES named The Limpet (Land Installed Marine Power Energy Transmitter) was developed by Wavegen Ltd and Queen's University in Belfast [20]. It is an OWC type WES with the capacity of $75 \mathrm{~kW}$ prototypes installed in Scotland, as shown in Fig 4. There are a lot of issues that hinder the commercial development of this type of OWC for the capacity of up to $500 \mathrm{~kW}$ [21]. The real issue was the performance and efficiency of OWC with a considerable start-up cost and the huge sum is required for R \& D. The limpet in the UK was decommissioned and a lot of money spent on maintenance. There is a scope of improvement by using variable pitch turbines [21]. By redesigning the structure of the OWC, a sufficiently large water column can be realised which enables the achievement of resonance, an example is the mighty whale which has a rated power of $110 \mathrm{~kW}$ $[15,16]$.

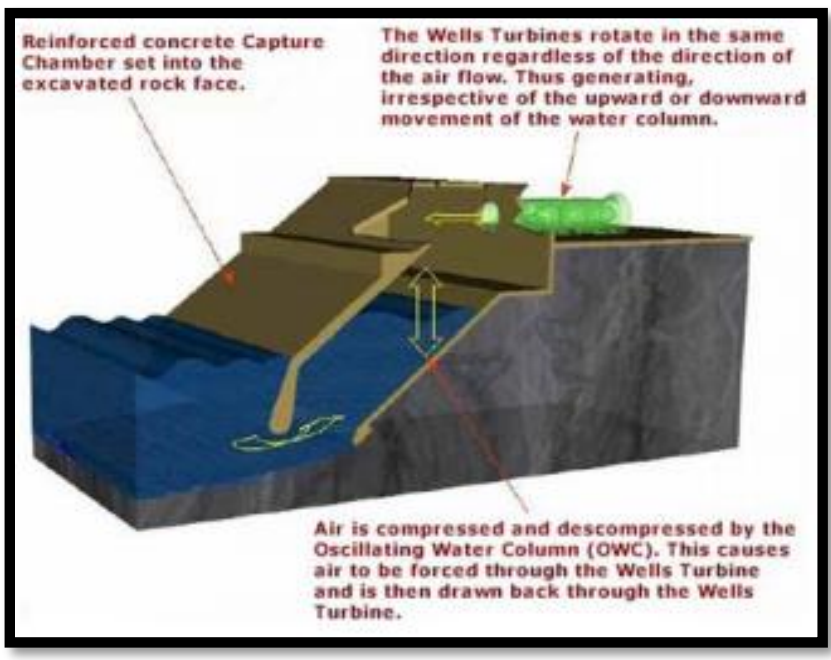

(a)

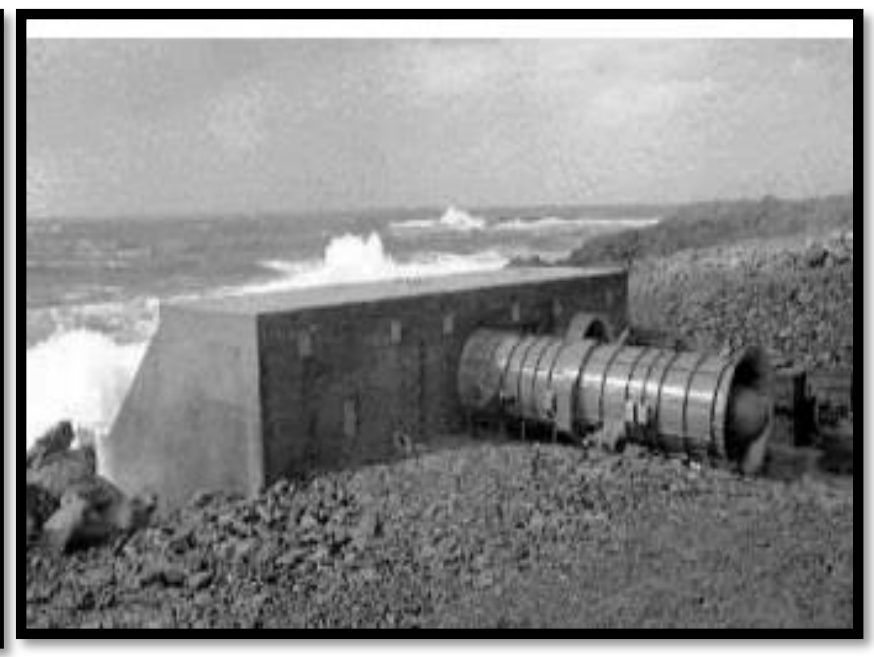

(b)

Fig. 4. Onshore WES named The Limpet (Land Installed Marine Power Energy Transmitter) developed by Wavegen Ltd and Queen's University in Belfast, UK shows (a) cross-sectional illustration [21] and (b) a photograph of the limpet [20] 


\section{Nearshore Wave energy systems (WES)}

There are a number of nearshore WES developed all over the world with different features and power generation capacity [17]. The main prototype device for water middle range water depth developed by Wavegen Ltd in the UK and it was Osprey works on the principle of OWC installed in seabed about less than 20 meters away from shore. The first prototype (Osprey 1) made up of steel body was failed during installation near in Scotland [7]. A new design of Osprey 2000 is developed with the capacity of $2 \mathrm{MW}$ and with hybridisation of wind turbine at $1.5 \mathrm{MW}$ as illustrated in Fig 5 [21]. It is a concrete-based design can be operated in the $15 \mathrm{~m}$ depth of water in $1 \mathrm{~km}$ of shore generating power for coastal area and there could be many environmental and geological issues with wind or wave energy devices installed closed to shore [21]. The main aim was to get the maximum amount of energy from nearshore location and a lot of work has been done for the success of this device and it's nearly out of its R \& D stage. There are a lot of other factors need to be taken into account like what if the new design fail? Is the new design sustainable? Even before installation further improvements are needed to reduce the constructional engineering costs. There is no full substantiation of its unit cost or the time needed to break-even the investments and actual efficiency of this device.

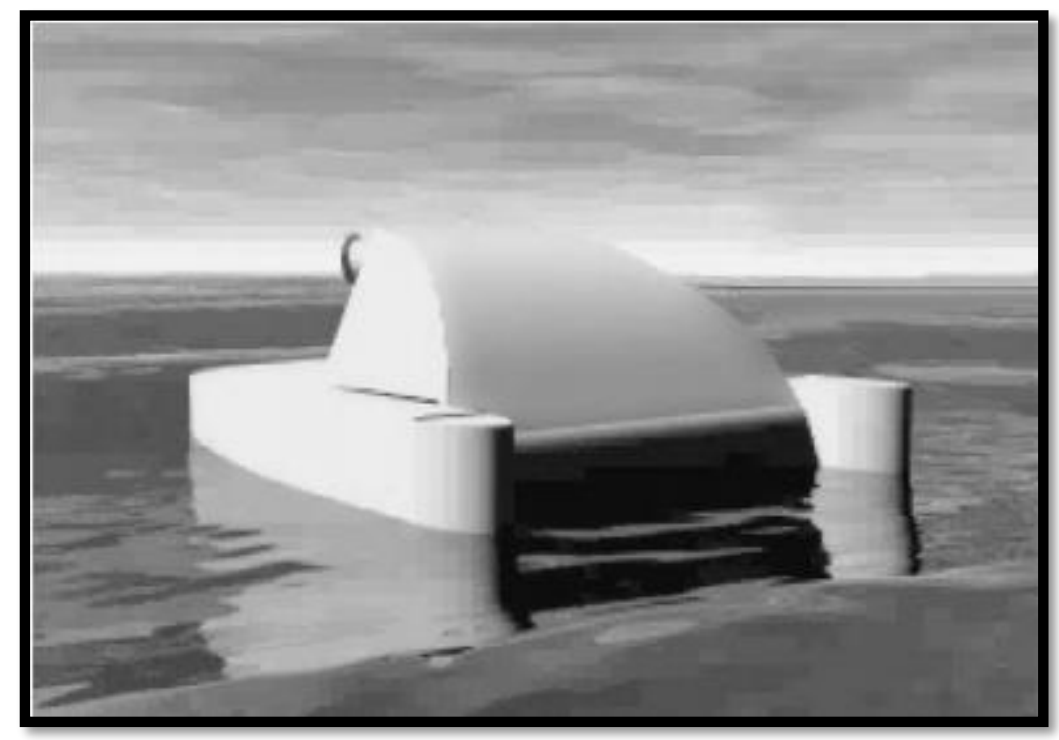

Fig. 5. An illustration of the onshore WES named The Osprey [21]

\section{Offshore Wave energy systems (WES)}

Offshore WES are considered to be most powerful with the chance of more energy extraction installed in deep water. A significant amount of energy can be extracted from waves by putting these devices close to the surface or they require easy mooring. The major characteristics of offshore WES are their complexity in design when compared to the first-generation designs or OWC. The existing designs features or sometimes fully submerged in water. They can harvest deep water wave which are very powerful. As they are very complex compared to the OWC, they possess additional problems relating to mooring, maintenance accessibility and requirements of long underwater electrical cables, which has placed high limitation to their full-scale development. [11,17]. Numerous prototypes have been developed and tested over the years and each prototype have different structures and dimensions with the only shared attributes being their ability to oscillate. There are a number of 
offshore WES installed in different countries with their own advantages and disadvantages, which are discussed in the following subsections.

\subsection{The Pelamis}

The Pelamis is a semi-submerged structure consists of cylindrical sections joined together [22]. The device is installed in the UK with a power rating of $375 \mathrm{~kW}$ and it is $130 \mathrm{~m}$ long with a diameter of 3.5 meters shown in Fig. 6 [21. Comprising of four cylinders sections connected by hinged joints, the device is aligned with the wave directions. Pelamis can be grouped under the devices that made it through R\&D comprising of rigorous testing at several scales to reaching full size testing stage. [12, 17]. The Pelamis exhibits minimum variation in inter-annual variability in full load hours $\left(R_{h}\right)$ which is the ratio of energy production $E_{o}$ to maximum rated power $P_{m}$ [23]. The resistibility of the hydraulic arm in the Pelamis enables it to supply high pressure oil to hydraulic motors that run the generator to produce electricity and this happens when the hinged joints movement produced waves which are resisted by the hydraulic arms [7].

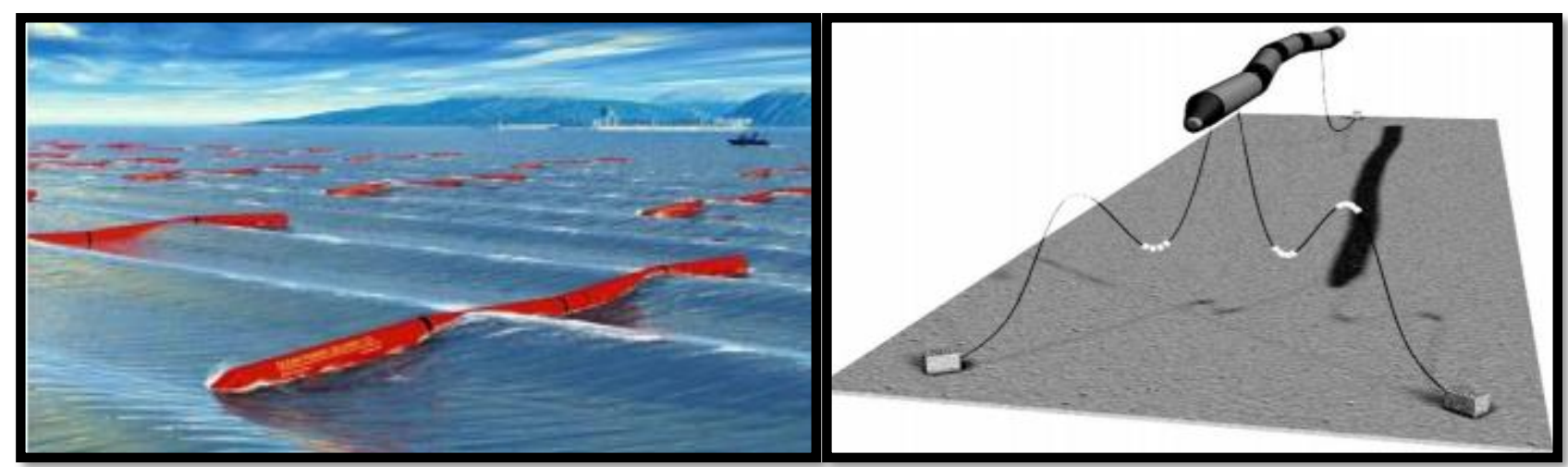

(a)

(b)

Fig. 6. The Pelamis type WES categorised as offshore showing (a) a photograph of semi-submerged structure [12] and (b) illustration of the Pelamis [21].

\subsection{The Archimedes Wave Swing:}

The Archimedes Wave Swing (AWS) is a full submerged heavy type WES consists of cylindrical airfilled chambers also called floater, it is fixed to the seabed and can move vertically from its base [24]. Its operation is dependent on the downward movement of the upper part during wave crest and a reverse movement during wave trough. By resisting this movement using a linear generator with the inner air pressure posing as a string, energy is generated [17]. The AWS installed in the UK with the capacity of $2 \mathrm{MW}$, currently in the finalizing stage, as shown in Fig. 7 [21, 25]. Relatively, this design is not as efficient as OWC but still many devices are tested in the sea at offshore locations and these devices are leaving the research and development stage and soon will be ready for commercialization. 


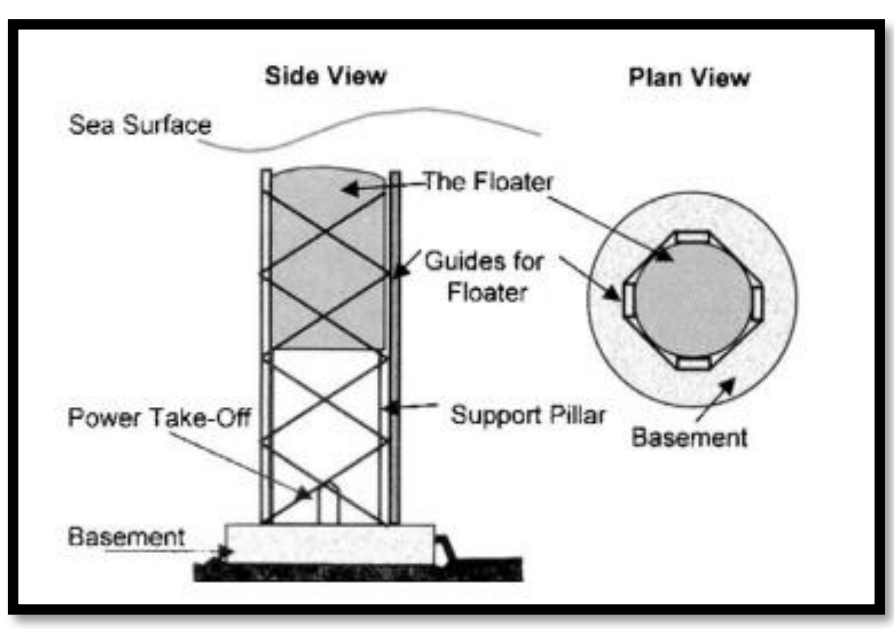

(a)

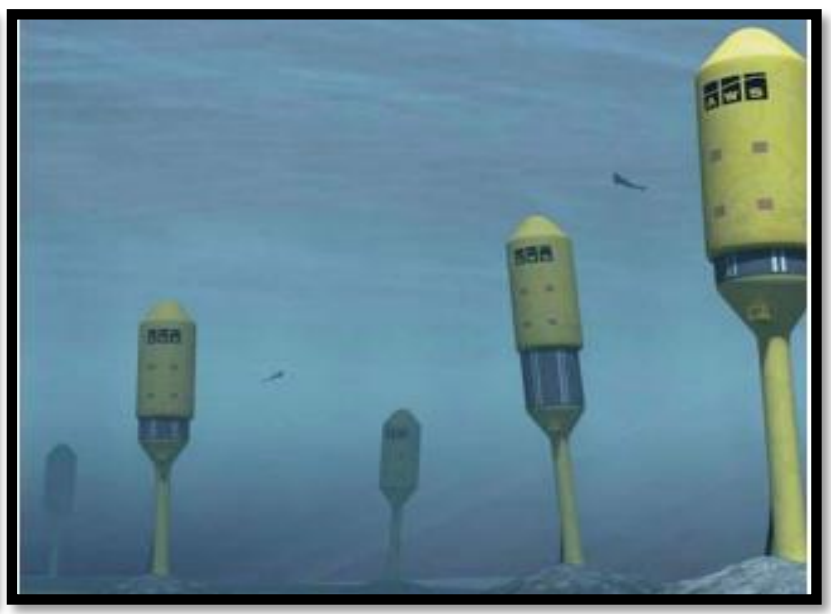

(b)

Fig. 7. The Archimedes Wave swing type WES showing (a) a schematic diagram [21] and (b) an illustration of it [25].

\subsection{Single Body heaving buoys}

Single body heaving buoys type WES is one of the oscillating body systems and are regarded as point absorbers which means their wavelength is way bigger than their horizontal dimension. Numerous devices of this concept have been developed and tested over the years; example is the Trondheim fjord buoy called the Norwegian buoy in 1983 as shown in Fig. 8. It features a floater which is spherical in shape and uses a universal joint for its connection to an anchor in the seabed, moving forward to 1990, an alternative device was featured which is a buoy attached by a cable to a bottom fixed structure tensioned by a spring device. The 1990 buoy uses a piston pump to supply high water to a hydraulic turbine $[15,17]$. Using a spar tant moored to the seabed by a cable, a heaving buoy was used to drive a linear electrical generator. The main components are the deep-draught spar and an annular saucer -shape buoy. By relative heaving to the spar only and stilted in other areas by a linear bearing system, a permanent magnet linear generator generates electricity by capitalizing on the imposed force on the spar by the relative velocity of the two bodies. This was developed in Sweden Oregon in 2008 [17].

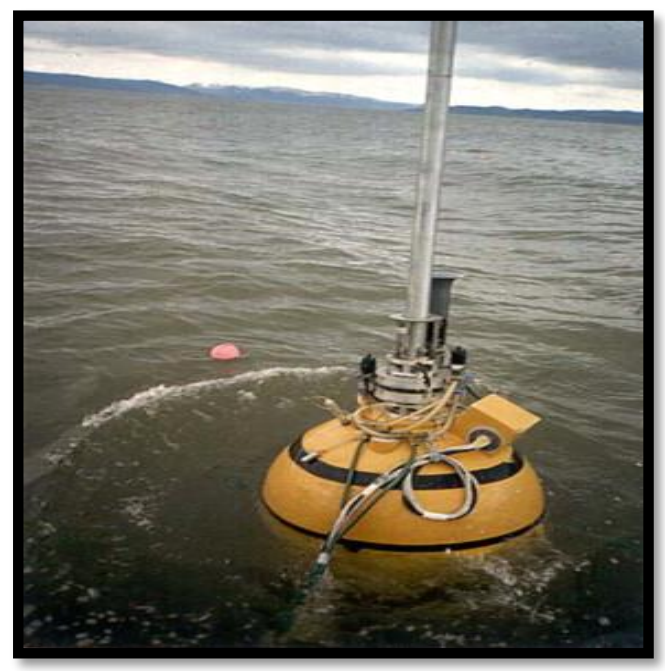

Fig. 8. Single body heaving buoys type WES showing a photograph of Norwegian heavy buoy Trondheim Fjord [17]. 


\subsection{Two body heaving buoys}

Two body heaving buoys overcomes the disadvantages presented by the single body heavy buoys, i.e. the difficulties arising from the distance between the free surface, the bottom and the tidal oscillations in sea level. This geared the development of multi body systems, represented by two bodies oscillation differently to produce energy, which depends on the hydrodynamics of the bodies. A typical example of two body system is the IPS buoy is shown in Fig. 9 [17]. It is made of an accelerating tube which comprises of a piston with an elongated rod mounted slidably. The piston up and down movement is dependent on the difference in the column water captured within the accelerated tube which has two open ends, and this serves as the energy absorbing device which is connected to the buoyant unit. The piston is limited and travels extent that curbs the liability to damage, which may result from excessive forces during very ferocious seas [17]. The whole invention operation rely on the rising and falling of the water which drags the floating buoyant to move relatively to the piston in the substantially quiescent column in the tube, but the piston would continue or tend to continue moving upward irrespective of the up and down water like movement of buoy, hence it drives the power take off (PTO) mechanism[15].

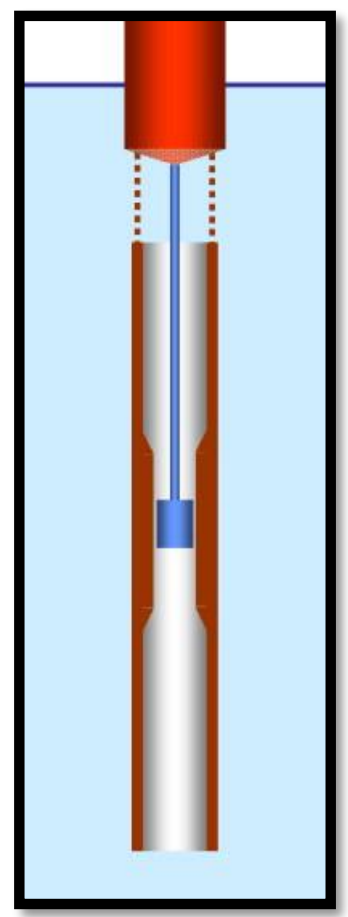

Fig. 9. A schematic diagram of IPS power buoy [17] is a two body heaving buoys type WES.

\subsection{Multi body heaving buoys-Overtopping}

Multibody heaving buoys WES can be at nearshore or offshore. Typically, they are made of a large set of point absorbers that shares common power take off and common frame reaction. They normally consist of an array of 21 asymmetric buoys using heave oscillation accompanied by a large floating structure own by a square planform with a very low resonance $[11,15,17]$. Overtopping converters appears to be unique at high wave crest, water is captured and stored in reservoir above the sea level. The water is then supplied back to the sea using hydraulic turbine. This device gathers waves into the central receiving part for upward flowing into the reservoir with the use of large curve reflectors. The water is then released back to the sea with the use of low head turbine [17]. An 
example is the Wave Dragon, 4-10 MW relying upon how lively the wave atmosphere is at the sending site [9]. It is an embodiment of the description above as it comprises of a collector, water, reservoir and a low head inner turbine. Fig. 10 [9] shows the overall general schematic of Over topping device Wave Dragon. One of the prototypes built in the island of Kvitsoy, Norway [26], features a collector linked to a rocky cliff with $60 \mathrm{~m}$, broad entrance. The other end of the channel connected to the converter is narrow which appears to be gradual from the reservoir. The waves enter the wide end of the channel and as they travel down the narrowing channel, wave height is amplified until its crest spill over a wall built to the height of the reservoir to fill the water reservoir. Hence, transformation of wave energy into potential energy gradually occur in the reservoir. Basically, the reservoir is task with the stable supply of water to the low head hydraulic turbine, therefore it must be ideally large to enable a smooth propagation of water overtopping from the converter [17].

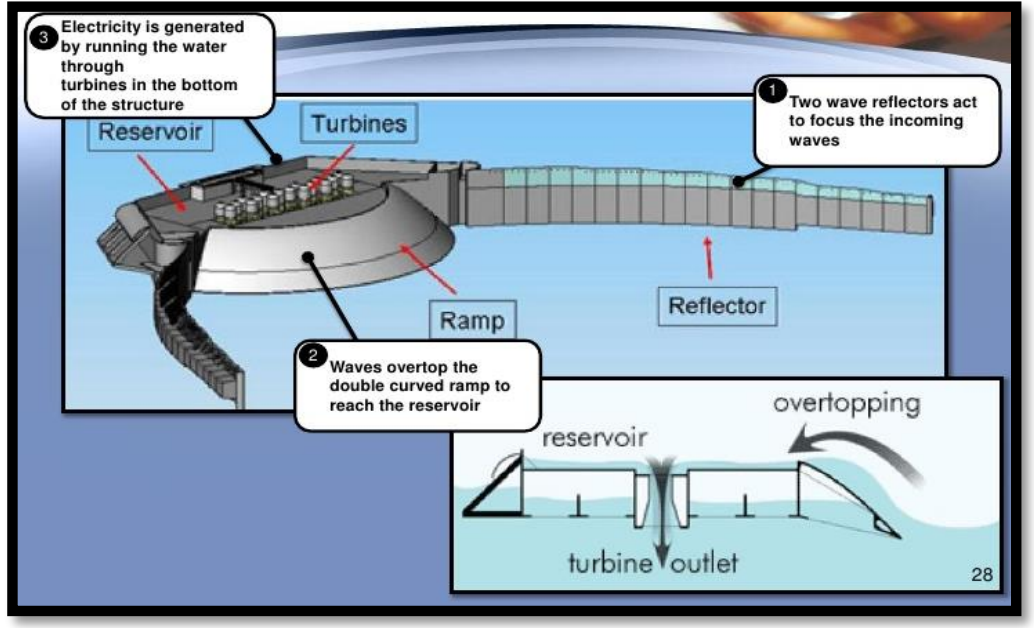

(a)

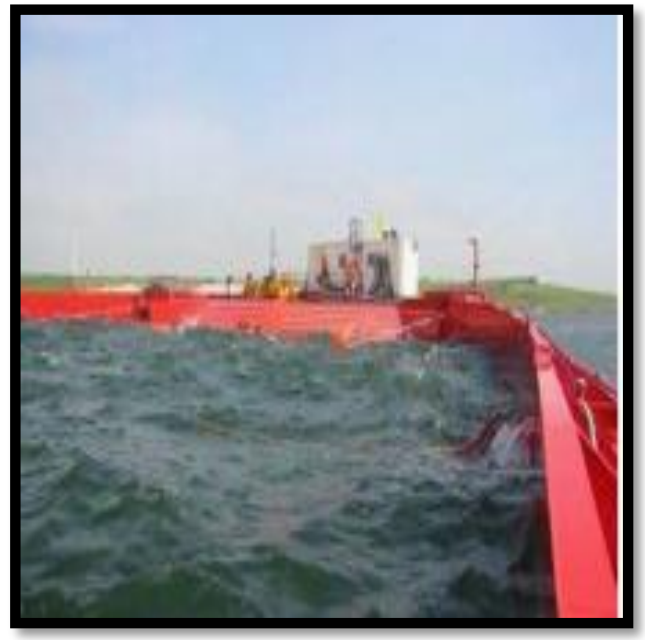

(b)

Fig. 10. shows (a) the overall general schematic of over topping device Wave Dragon which is multi body heaving buoys WES [8] and a photograph illustrating reflector [15].

\subsection{Impact Devices}

Impact devices type of WES converters are enunciated, or adaptable structures situated opposite to the wave bearing. Along these lines, the deflector moves forward and backward because of wave sway. A precedent is the Aquamarine Power Oyster capacity of $800 \mathrm{~kW}$ [9]. Fig. 11 shows the practical example or hardware of aquamarine power oyster [9].

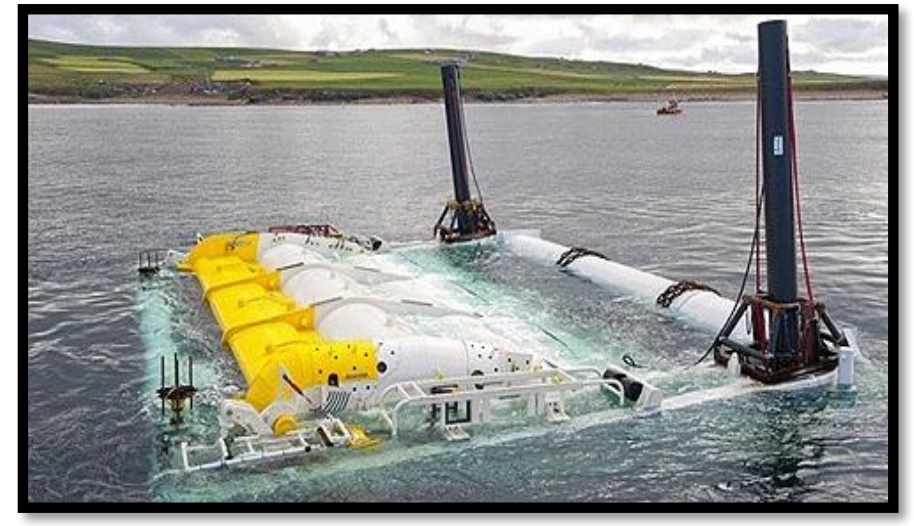

Fig. 11. A practical example of the Aquamarine Power Oyster [9]. 


\section{Discussions on ALBATERBN UK case study}

ALBATERN is a company in the UK that utilizes the wave energy to produce the electricity using OWC type of WES in the form of arrays. This company was founded in 2007 by David Finlay and was a self-supported company until 2010 and all the developments in the technology was on self-basis. At that time, it was very early for this technology to get useful results which made the investors see the improvement first somehow afterward it received funding.

The Wave Farm is in Scotland and the main purpose of the farm was to supply electricity to the supplementary isolated fish farms, which were relying on the diesel generators. It was a coordination between ALBATERN and Marine Harvest Scotland, ALBATERN owns the technology. This case study shows that lesson learnt from this project which clearly means that supply was not enough for the great demand or was only useful on a domestic scale or small scale only. So, it is also clear that it was a prototype of the technology that is being used and project is taken as an experimental project to test the technology to convert wave energy to electrical and to test the potential of the wave energy available. According to the ALBATERN, the Wave Net new and unique design allows it to track the full orbital motion of the fluid particles in the ocean waves. If we use the efficient wave energy resource at a suitable location and install large arrays of OWC (ALBATERN technology) then $300 \mathrm{MW} / \mathrm{km}^{2}$ is possible but a lot of improvement must be done in the technology for that purpose. If compared to wind energy, which is $10 \mathrm{MW} / \mathrm{km}^{2}$ offshore. So, if we come out of the solution to utilise the wave energy at a maximum then It has the potential to cover $20 \%$ of UK energy requirements [27].

According to the analysis and point of view after studying the case study of ALBATERN [27], the main barriers in utilising this technology are:

- As wave energy have high potential and high density offshore and designing the equipment for survival in water for a long time is quite challenging.

- Installation of the equipment in the sea and maintenance of the devices as per required will be very challenging and costly.

- Wave energy potential near the shore is not reliable and doesn't have that potential as compared to the offshore and using low head turbines for near shore is also challenging.

- Cost and maintenance of the transmission lines to utilize the electrical energy

- Relying entirely on all the energy from offshore devices could pose challenges.

- Financial support which is very crucial thing in improving the technology and convincing the investors to invest in this technology and R\&D department related to this technology is a must thing.

- Capital cost is very high.

It is imperative from this case study that a lot of work is being required for getting useful results from the technology and utilizing the wave energy into electrical energy cost-effectively. However, wave energy has the potential to cover the great amount of energy requirements in the UK. But the question remains the same: how to utilise this energy at a manageable cost not by the means that energy produced by the wave energy is costing more as compared to other renewable energy sources [28]. Beside ALBATERN Wave Net UK, many other companies have also tested WES but on the experimental basis further improvement is required not only on the devices and technology but also in analysing the best location for suitable and reliable wave energy. Research is being carried out and is still in progress to coming up with a best solution to utilise the wave energy to its extent. 


\section{Prognostication of Wave Energy in the UK}

Wave energy exploits the movement of the wind across the surface of the sea to provide an infinite, carbon-free energy source for electricity generation. This can possibly provide a significant influence on electricity generation supply in the UK, meeting up to $20 \%$ of the UK's electricity demand. This represents 30-50 MW volume of electrical energy of $27 \mathrm{GW}$ by 2050 as technology within the industry develops and matures. Studies show that developing marine energy resources in the UK can save 60 metric tons of carbon dioxide by 2025 and aid in the UK meeting renewable energy objectives, Table 1 shows the list of companies operating wave energy plants in UK [29].

Table 1

\begin{tabular}{lllll} 
UK Wave Energy Farms [29] & & & & \\
\hline Companies & WES Devices & WEC Location & Year & $\begin{array}{l}\text { Energy } \\
\text { conversion }\end{array}$ \\
\hline $\begin{array}{l}\text { ALBATERBN Wave NET } \\
\text { ALBATERBN }\end{array}$ & Multi Point offshore & 2010 & $\begin{array}{l}\text { Hydraulic / } \\
\text { electric / DC }\end{array}$ \\
\hline AMOG, AEP WEC & Absorber array & & 2019 & Electric \\
Falmouth & $\begin{array}{l}\text { Surface dynamic } \\
\text { Vibration absorber }\end{array}$ & Off-shore & & \\
\hline AWS-iii & Surface following & Off-Shore & 2010 & Air turbine \\
AWS Ocean energy & Attenuator & & & \\
\hline $\begin{array}{l}\text { C-Cell } \\
\text { Zyba Renewables }\end{array}$ & Oscillating Wave & Near-Shore & 2015 & Hydraulic \\
\hline SeaRaser & surge Converters & and Off-shore & & \\
Alvin Smith (Dartmouth Wave Energy) & Buoy & Near-Shore & 2008 & Hydraulic \\
\hline
\end{tabular}

\section{Feasibility and efficiency of WES}

The power takes off (PTO) efficiency is crucially important as the overall output depends on the optimum energy harness from WES that will improve its competitive prowess with other renewable technologies and further reduce the cost of WEC energy production. Researchers and scientists have rendered great contributions to the development and improvement of WES. With any inaccurate predictions could cause misconception and jeopardise the future prospects of WES projects as the complexity of WES requires a near perfect planning and prediction of the characteristics of its operation parameters. An example was the effect of non- factual sea floor topography on the Islay limpet. A prediction of $150 \mathrm{~kW}$ annual average output was made based on a model test. However, a difference of $30 \%$ higher incident wave power capability than the prototype acquired during physical survey. Further future survey gives a lesser cliff edge water level albeit just $1 \mathrm{~m}$ less than expected and a seabed slope shifting $60 \mathrm{~m}$ away in contrast to a cliff edge starting point that was initially realised in the first survey, this dynamic reduces the capture power by $50 \%$ compared to what was achieved in the model test [16]. This serves as an indication that modelling can be a good approach to understudy and gain insight into wave power plant operation performance, real time testing and practicing is the core way of achieving the optimal output enough to place the technology at the same competitive edge with other renewable systems.

An estimation of the wave energy conversion efficiency was reported [15]. The study uses the Era-interim global atmospheric reanalysis wave data from the European centre for medium range weather forecast (ECMWF), with focus on height of combined wind waves and swells, wave period and mean wave duration [15]. The data was used to evaluate the performances of 12 WES with their rated powers as listed in Table 2. This was based on the combination of the power matrices of the wave generators with bivariate distribution obtained from the investigation of wave spatial distribution of the wave power using a non-dimensional normalised wave power index. An estimate 
of expected amount of electricity was performed with focus assessment on normalised electric power, capture width and capacity factor [15].

Table 2

Typical power rating of WES

\begin{tabular}{ll}
\hline Type & Power rating (kW) \\
\hline Wave dragon & 5900 \\
\hline Pontoon power converter & 7619 \\
\hline Sea power & 3587 \\
\hline Ocean Energy buoy (OE) & 2880 \\
\hline Wave star & 2709 \\
\hline Archimedes wave swing (AWS) & 2470 \\
\hline Wave Bob & 1000 \\
\hline Pelamis & 750 \\
\hline Oceantec & 500 \\
\hline Ceto & 260 \\
\hline Aqua Buoy & 250 \\
\hline Seabased AB & 15 \\
\hline
\end{tabular}

Based on the power rating of the WES, they are cross examined according to the various coastal environments relating to different wave characteristics. In the end it was highlighted that, wave dragon stands out impressively in terms of efficiency and energy output and it was recommended as a system compatible with in projects where coastal protection is paramount and projects where there is a limitation regarding beach erosion generated by wave action due to its high capture width standing at range of 70-80m [15].

According to [30], a FEM (finite element model) was implemented to study the efficiency of arrays of OWC type WES. It utilises a modelled single isolated OWC device to form two different arrays of OWC devices, which are evenly spaced on a rectangular grid. The outcome of the experiment was defined into two different efficiencies to form a mean efficiency and the mean power capture efficiency appears to be higher than the efficiency of single OWC. Subsequently, it was highlighted that the overall maximum mean efficiency for the two different arrays mentioned earlier reached near resonant frequency when the wave incidence angle is zero of the models. The peak efficiency of the array is predicted to be $30 \%$ higher than the peak efficiency attained with the single OWC type WES.

According to [31], an experimental study on the efficiency of the submerged plate WES was conducted under various conditions using the ratio of the water flow power to wave power to determine the efficiency by using a hydraulic Lab of ministry of communication in Turkey. With various wave properties and focus on wave periods and wave height, the water flow below the plate and wavelength are measured for 8 various conditions. This allows the velocity of water flow below the plate and maximum flow velocities to be measured and this allows the efficiency of the plate wave energy to be calculated. The efficiency of the plate with no attachment records the minimum efficiency of $5.41 \%$ and highest efficiency value of about $60 \%$ was recorded for plate which has a wall below the plate with a distance set to separate the uppermost part of the wall and the bottom of the pole. The study by [31] finally concluded that plate WES efficiency can be enhanced to $60 \%$ when a structure is located below the plate.

The Pelamis, as discussed earlier, is one of a few WES that made it to the real testing stage, it gives insight into the efficiency of a prototype Pelamis of the European marine energy centre (EMEC). The report highlighted within a window of five minutes the instantaneous power absorbed for the first joint of the prototype and the smooth electrical power of the joint. A conversion efficiency of $64 \%$ with a total power output of $150 \mathrm{~kW}$ for a $30 \mathrm{~min}$ average time was recorded for the prototype. 
However, the said power input is not specific to Pelamis [11,12], but a typical feature of a wave power machine. This later brings about a P2 Pelamis promising more efficient use of structure, power capture increase and higher conversion efficiency of 20-30\% and lower cut in wave height to enable flexibility in wave absorption capability (small sea capture) [12]. An improvement from P1 to P2 Pelamis achieved the conversion efficiency to about 70\% (wave to wire efficiency) for a 30 mins sample. Assumptions can be made on whether $70 \%$ can continuously be realised such as the variation in wave resources due to sea characteristics as the device is an offshore device. This could not guarantee adequate maximum wave availability and a possibly harsh offshore environment. It makes access to repair and maintain equipment difficult [12]

\section{Environmental challenges of wave energy systems (WES)}

Environmental challenges of WES can be determined based on the location and size of installation. Dredging is one of the activities performed during the installation of wave energy converters which causes a lot of disturbances to sea habitat. However, subsequent to the deployment phase of WES, the solid substrates of bottom WES serve as artificial reefs for soft bottom habitats. Potentially, it serves as larval sites and this can attract juvenile and adult marine organisms and possibly becomes habitat for fish crabs and lobsters [32,33]. Studies have shown that the structural volume and degree of complexity of artificial reefs can contribute to species abundance [33]. Apart from the benefit provided by the bottom substrates to sea habitats, the floating part of the wave converters attracts juvenile and adult fish as it serves non-exhaustively as resting solace, protection from predators and food available region [32]. The detriment of wave converters on marine habitats is characterized mainly around the effect of suspended particles produced during dredging which may affect the feeding behaviour of habitats and possible burying of eggs, algae and benthic organisms. Apart from dredging, the noise produced as a result of drilling, cable movement and laying and placing during installation and maintenance of WES may affect the auditory of species close to the area and may cause them to vacate their habitat, and possibly make them vulnerable to predators [8]. Considering the biofouling of organisms on WES such as buoy, literature has highlighted, material degradation, weight increase and shape alteration as some of the negative effects of biofouling which possess a threat on the efficiency of wave absorbing devices [7][8]. An assessment on the effect of electromagnetic field indicates that, irrespective of the WES location, the related electromagnetic fields present will be detrimental, to marine habitats and this can adversely affect their fertility and reproduction [33]. Low numbers of mature devices limit the study/outcome/experience in areas of environmental adversity, although adversities foreseen have been relatively low.

\section{Prognostication of zero energy coastline houses in the UK}

There is an immense scope of building retrofits and new build construction of zero energy houses in the UK [34-39]. According to UK Government regulation 25B introduced into the Building regulations in 2012 [40] to transpose buildings to nearly zero energy buildings [41,42] and PartL1A 2016 recommended zero energy homes with an equivalent zero $\mathrm{CO}_{2}$ emissions. It can be achieved with effective wall and windows insulations such as vacuum glazing [43-49], triple vacuum glazing [50-54] and/or vacuum insulation panel with semi-transparent PV films [41, 42] on building façade for minimising the heat loss and generating electricity. More importantly, it requires standalone power generation to distant coastline community houses. To achieve the net zero $\mathrm{CO}_{2}$ emissions target per household, the use of electric vehicles [55] and charging stations integrated to off-grid 
$[56,57]$ WES can be one of the prognostications. The utilization and conversion of the waste radiative heat from the domestic boilers to electricity will further speed up this vision [58-61]. A WES can be an alternative to wind and PV panels, specifically to the coastline houses in the UK. According to the seaside economy report [62], there are 43 primary seaside towns around the coast of Britain, in which 37 are in England, UK, encompassing a collective population of 2.9 million that signify around $5.7 \%$ of the population of England as a whole. The location of the UK is also one of the major determinants for the future success of wave energy projects, as the UK is located at the long fetch of "Atlantic Ocean" and has the wind direction from the west. The available resource of the wave energy in the UK is around $120 \mathrm{GW}$.

The progress in the development of standalone WES is still in its initial stages. Extraction of wave energy is more appealing and predictable as compared to wind and photovoltaic systems. Implementation of wave energy commercially has been found to be a very time consuming and expensive process [63]. Wind energy is developed from small scale to industrial scale by developing small devices and later they were scaled-up. The same approach should be implemented to WES, first small standalone devices and later implemented town or citywide around the coastline in the UK. In this same concept, Wave energy converters should be sustainable and reliable in extreme wave conditions and their maintenance and monitoring should be cost-efficient. Wave energy has to compete against more advanced renewable technologies where investments are already made. Wave energy devices require large investments unless investors see a huge advantage. They will not invest in this technology moreover the technology is not fully developed so there will be research and development costs as well. In this situation investments on these technologies become more difficult. In this context, the step professionals and researchers can take is to take part in the effort in order to shape the wave energy technology more reliable, efficient and cost-effective.

Although the concentration of the scientists and practitioners is less toward the wave energy but still, the overall potential of the wave energy for the provision of renewable energy is very high. Currently installed WES around the oceanic coastline has the capacity to produce $60-80 \%$ of the useful energy. The progress of the wave energy also includes the availability of the sites as well as the technical potential to cater to the issues regarding wave energy. The predictability of the wave energy is also very effective as compared to the other renewable energy sources. It is easy to account for the capacity of WES for the production of electricity. The main reasons behind these characters of the wave energy are that once the waves are created that concisely transmit the energy for a particular time and distances. History also demonstrates that the first patent for the wave energy was registered in Paris in 1799 and after two centuries a total of 340 British patents for the wave energy devices has been registered. The progress in the wave energy is also released from the increasing interest in the research and development of the wave energy where numerous prototype devices have been launched to improve the technology. Still, the wave energy is at the prototype and R\&D stage [64].

The commercial status of wave energy is still a debated field in the research paradigm, mainly, due to high start-up cost for standalone WES. However, it will certainly be beneficial to isolated coastal communities and the overall wave energy has a good perspective for the commercial icons at a large scale [7]. In the next few years, it is expected that commercial devices for the wave energy will be deployed in the UK. This deployment in the UK for the wave energy is dependent on the technical performance and the reliability of the devices. It is also evident from the research that the wave energy also has the export potential. The UK government has planned to export the 6MW wave energy to the world in the coming years. The wave energy market can further be flourished as it is considered as the competitive energy source for conventional electricity production, it will contribute effectively as an energy resource as well as toward the economy of the UK. 


\section{Conclusions}

This paper reviews the current status, challenges and prognostications of wave energy systems (WES). It is imperative from this review that WES have momentous scope in the UK that could deliver the UK's net zero energy target by 2050. This paper exhibited a brief review of the onshore, nearshore and offshore WES technologies, particular focus was made to the scope in the UK. The feasibility and efficiency of WES study imply that the power take off (PTO) efficiency is crucially important as the overall output depends on the optimum energy harness from WES that will improve its competitive prowess with other renewable technologies and further reduce the cost of WEC energy production. This review highlights that Pelamis could achieve conversion efficiency of $64 \%$ with a total power output of $150 \mathrm{~kW}$ for a short period and depends on the variation in wave resources due to sea characteristics. This study implicates one of prognostications that developing marine energy resources in the UK can save 60 metric tons of carbon dioxide by 2025 and aid in the UK meeting renewable energy objectives. Whilst, the strength of the UK wave energy farms is growing. The ALBATERBN UK case study review shows that capital cost along with maintenance costs are considerable issues but can be minimised by increasing the UK manufacturing capacity. Beside ALBATERN Wave Net UK, many other companies have also tested (theoretically and experimentally) WES and further improvement is required not only on the devices and technology but also in analysing the best location for suitable and reliable WES. This study also concluded that WES can pose environmental challenges such as alterations of water column to biota and sea-bed habitats, dredging, noise and vibrations and space. The prognostication of zero energy coastline houses arises due to the location of the UK, which is one of the major determinants for the future success of wave energy projects, as the UK is located at the long fetch of the Atlantic Ocean and has the wind direction from the west. The available resource of the wave energy in the UK is around $120 \mathrm{GW}$. In Britain, there are 43 primary seaside towns around the coast in which 37 are in England that encompass a collective population of 2.9 million and signify around $5.7 \%$ of the population of England as a whole where the zero energy coastline house projects can be initiated with WES. The progress in the development of standalone WES for a vision of zero energy coastline houses is still in its initial stages.

\section{Acknowledgment}

This research work was supported by the London South Bank University, Solar Thermal Vacuum Engineering Research Group. This research is self-funded and a self-initiated collaborative research work that did not receive any specific grant from funding agencies in the public, commercial, or notfor-profit sectors.

\section{References}

[1] Cairney, Paul, Aileen McHarg, Nicola McEwen, and Karen Turner. "How to conceptualize energy law and policy for an interdisciplinary audience: The case of post-Brexit UK." Energy Policy 129 (2019): 459-466. https://doi.org/10.1016/j.enpol.2019.02.022

[2] EPRSC: HM Government, "The Clean Growth Strategy," (2017). https://www.gov.uk/government/publications/clean-growth-strategy.

[3] Reeve, D. E., Y. Chen, Shunqi Pan, V. Magar, D. J. Simmonds, and A. Zacharioudaki. "An investigation of the impacts of climate change on wave energy generation: The Wave Hub, Cornwall, UK." Renewable Energy 36, no. 9 (2011): 2404-2413. https://doi.org/10.1016/j.renene.2011.02.020

[4] Memon, S., T. Katsura, A. Radwan, S. Zhang, A. A. Serageldin, E. M. Abo-Zahhad, S. Sergey et al. "Modern eminence and concise critique of solar thermal energy and vacuum insulation technologies for sustainable lowcarbon infrastructure." International Journal of Solar Thermal Vacuum Engineering 1, no. 1 (2020): 52-71. ISSN online (2716-6953). 
https://doi.org/10.37934/stve.1.1.5271

[5] Hussain, Akhtar, Syed Muhammad Arif, and Muhammad Aslam. "Emerging renewable and sustainable energy technologies: State of the art." Renewable and Sustainable Energy Reviews 71 (2017): 12-28.

https://doi.org/10.1016/j.rser.2016.12.033

[6] Wilberforce, Tabbi, Zaki El Hassan, A. Durrant, J. Thompson, Bassel Soudan, and A. Ghani Olabi. "Overview of ocean power technology." Energy 175 (2019): 165-181.

https://doi.org/10.1016/j.energy.2019.03.068

[7] Titah-Benbouzid, Hosna, and Mohamed Benbouzid. "An up-to-date technologies review and evaluation of wave energy converters." (2015).

[8] López, Iraide, Jon Andreu, Salvador Ceballos, Iñigo Martínez De Alegría, and Iñigo Kortabarria. "Review of wave energy technologies and the necessary power-equipment." Renewable and sustainable energy reviews 27 (2013): 413-434.

https://doi.org/10.1016/j.rser.2013.07.009

[9] Barstow, Stephen, Gunnar Mørk, Lasse Lønseth, and Jan Petter Mathisen. "WorldWaves wave energy resource assessments from the deep ocean to the coast." Journal of Energy and Power Engineering 5, no. 8 (2011): 730742.

[10] Thorpe, T. W. "An overview of wave energy technologies: status, performance and costs." Wave power: moving towards commercial viability 26 (1999): 50-120.

[11] Ozkop, Emre, and Ismail H. Altas. "Control, power and electrical components in wave energy conversion systems: A review of the technologies." Renewable and Sustainable Energy Reviews 67 (2017): 106-115. https://doi.org/10.1016/j.rser.2016.09.012

[12] Yemm, Richard, David Pizer, Chris Retzler, and Ross Henderson. "Pelamis: experience from concept to connection." Philosophical Transactions of the Royal Society A: Mathematical, Physical and Engineering Sciences 370, no. 1959 (2012): 365-380.

[13] Evans, D. V. "Power from water waves." Annual review of Fluid mechanics 13, no. 1 (1981): $157-187$. https://doi.org/10.1146/annurev.fl.13.010181.001105

[14] Ross, David. Power from the Waves. Oxford University Press, USA, 1995.

[15] Rusu, Eugen. "Evaluation of the wave energy conversion efficiency in various coastal environments." Energies 7 , no. 6 (2014): 4002-4018. https://doi.org/10.3390/en7064002

[16] Boake, Cuan B., Trevor JT Whittaker, Matt Folley, and Hamish Ellen. "Overview and initial operational experience of the LIMPET wave energy plant." In The Twelfth International Offshore and Polar Engineering Conference. International Society of Offshore and Polar Engineers, 2002.

[17] Antonio, F. de O. "Wave energy utilization: A review of the technologies." Renewable and sustainable energy reviews 14, no. 3 (2010): 899-918.

https://doi.org/10.1016/j.rser.2009.11.003

[18] Mishra, Sunil Kumar, Shubhi Purwar, and Nand Kishor. "Maximizing output power in oscillating water column wave power plants: An optimization based MPPT algorithm." Technologies 6, no. 1 (2018): 15.

https://doi.org/10.3390/technologies6010015

[19] Pecher, Arthur, J. P. Kofoed, I. Le Crom, F. Neumann, and Eduardo de Brito Azevedo. "Performance assessment of the Pico OWC power plant following the EquiMar Methodology." In The Twenty-first International Offshore and Polar Engineering Conference. International Society of Offshore and Polar Engineers, 2011.

[20] Whittaker, T. J. T., W. Beattie, M. Folley, C. Boake, A. Wright, M. Osterried, and T. Heath. "The Limpet wave power project-The first years of operation." Renewable Energy (2004).

[21] Clément, Alain, Pat McCullen, António Falcão, Antonio Fiorentino, Fred Gardner, Karin Hammarlund, George Lemonis et al. "Wave energy in Europe: current status and perspectives." Renewable and sustainable energy reviews 6, no. 5 (2002): 405-431.

[22] Henderson, Ross. "Design, simulation, and testing of a novel hydraulic power take-off system for the Pelamis wave energy converter." Renewable energy 31, no. 2 (2006): 271-283.

https://doi.org/10.1016/j.renene.2005.08.021

[23] Morim, Joao, Nick Cartwright, Mark Hemer, Amir Etemad-Shahidi, and Darrell Strauss. "Inter-and intra-annual variability of potential power production from wave energy converters." Energy 169 (2019): 1224-1241. https://doi.org/10.1016/j.energy.2018.12.080

[24] Valério, Duarte, Pedro Beirão, and José Sá da Costa. "Optimisation of wave energy extraction with the Archimedes Wave Swing." Ocean Engineering 34, no. 17-18 (2007): 2330-2344. 
https://doi.org/10.1016/j.oceaneng.2007.05.009

[25] Uihlein, Andreas, and Davide Magagna. "Wave and tidal current energy-A review of the current state of research beyond technology." Renewable and Sustainable Energy Reviews 58 (2016): 1070-1081.

https://doi.org/10.1016/j.rser.2015.12.284

[26] Kofoed, Jens Peter, Peter Frigaard, Erik Friis-Madsen, and Hans Chr Sørensen. "Prototype testing of the wave energy converter wave dragon." Renewable energy 31, no. 2 (2006): 181-189.

https://doi.org/10.1016/j.renene.2005.09.005

[27] Vogler, Arne, and Vengatesan Venugopal. "Wave data analysis for a semi-sheltered site in the Inner Hebrides of Scotland suitable for small scale WEC development." Ocean Engineering 126 (2016): 374-383. https://doi.org/10.1016/j.oceaneng.2016.09.028

[28] Shi, Hongda, Shuting Huang, and Feifei Cao. "Hydrodynamic performance and power absorption of a multifreedom buoy wave energy device." Ocean Engineering 172 (2019): 541-549.

https://doi.org/10.1016/j.oceaneng.2018.12.005

[29] Azimov, Ulugbek, and Martin Birkett. "Feasibility study and design of an ocean wave power generation station integrated with a decommissioned offshore oil platform in UK waters." International Journal of Energy and Environment 8, no. 2 (2017): 161-174.

[30] Nader, Jean-Roch, Song-Ping Zhu, Paul Cooper, and Brad Stappenbelt. "A finite-element study of the efficiency of arrays of oscillating water column wave energy converters." Ocean Engineering 43 (2012): 72-81.

https://doi.org/10.1016/j.oceaneng.2012.01.022

[31] Orer, G., and Aydoğan Ozdamar. "An experimental study on the efficiency of the submerged plate wave energy converter." Renewable Energy 32, no. 8 (2007): 1317-1327.

https://doi.org/10.1016/j.renene.2006.06.008

[32] Lin, Lan, and Haitao Yu. "Offshore wave energy generation devices: impacts on ocean bio-environment." Acta Ecologica Sinica 32, no. 3 (2012): 117-122.

https://doi.org/10.1016/j.chnaes.2012.02.007

[33] Langhamer, Olivia, Kalle Haikonen, and Jan Sundberg. "Wave power-Sustainable energy or environmentally costly? A review with special emphasis on linear wave energy converters." Renewable and Sustainable Energy Reviews 14, no. 4 (2010): 1329-1335.

https://doi.org/10.1016/j.rser.2009.11.016

[34] Memon, Saim, and Philip C. Eames. "Predicting the solar energy and space-heating energy performance for solidwall detached house retrofitted with the composite edge-sealed triple vacuum glazing." Energy Procedia 122 (2017): 565-570.

https://doi.org/10.1016/j.egypro.2017.07.419

[35] Memon, Saim. "Analysing the potential of retrofitting ultra-low heat loss triple vacuum glazed windows to an existing UK solid wall dwelling." International Journal of Renewable Energy Development (IJRED) 3, no. 3 (2014): 161-174.

https://doi.org/10.14710/ijred.3.3.161-174

[36] Memon, Saim, and Philip C. Eames. "Heat load and solar gain prediction for solid wall dwellings retrofitted with triple vacuum glazing for selected window to wall area ratios." In World Renewable Energy Forum, WREF 2012, vol. 6, pp. 4636-4643. ASES, 2012. ISBN: 9781622760923

[37] Memon, Saim, and Philip C. Eames. "Solar energy gain and space-heating energy supply analyses for solid-wall dwelling retrofitted with the experimentally achievable U-value of novel triple vacuum glazing." Journal of Daylighting 4, no. 1 (2017): 15-25.

https://doi.org/10.15627/jd.2017.2

[38] Memon, Saim. "Investigating energy saving performance interdependencies with retrofit triple vacuum glazing for use in UK dwelling with solid walls, Sustainable Development on Building and Environment." In Sustainable Development on Building and Environment: Proceedings of the 7th International Conference, 2015. ISBN-13: 9780993120701.

[39] Ahmed, Mostafa, Ali Radwan, Ahmed Serageldin, Saim Memon, Takao Katsura, and Katsunori Nagano. "Thermal Analysis of a New Sliding Smart Window Integrated with Vacuum Insulation, Photovoltaic, and Phase Change Material." Sustainability 12, no. 19 (2020): 7846.

https://doi.org/10.3390/su12197846

[40] Barnshaw, Stephen. "The zero carbon and nearly zero energy standards in new buildings." Journal of Building Survey, Appraisal \& Valuation 6, no. 4 (2018): 344-349. 
[41] Radwan, Ali, Takao Katsura, Saim Memon, Ahmed A. Serageldin, Makoto Nakamura, and Katsunori Nagano. "Thermal and electrical performances of semi-transparent photovoltaic glazing integrated with translucent vacuum insulation panel and vacuum glazing." Energy Conversion and Management 215 (2020): 112920. https://doi.org/10.1016/j.enconman.2020.112920

[42] Katsura, Takao, Saim Memon, Ali Radwan, Makoto Nakamura, and Katsunori Nagano. "Thermal performance analysis of a new structured-core translucent vacuum insulation panel in comparison to vacuum glazing: Experimental and theoretically validated analyses." Solar Energy 199 (2020): 326-346. https://doi.org/10.1016/j.solener.2020.02.030

[43] Memon, Saim, Yueping Fang, and Philip C. Eames. "The influence of low-temperature surface induction on evacuation, pump-out hole sealing and thermal performance of composite edge-sealed vacuum insulated glazing." Renewable energy 135 (2019): 450-464.

https://doi.org/10.1016/j.renene.2018.12.025

[44] Memon, Saim. "Design, fabrication and performance analysis of vacuum glazing units fabricated with low and high temperature hermetic glass edge sealing materials." PhD diss., Loughborough University, 2013. https://dspace.lboro.ac.uk/2134/14562

[45] Fang, Yueping, Saim Memon, Jingqing Peng, Mark Tyrer, and Tingzhen Ming. "Solar thermal performance of two innovative configurations of air-vacuum layered triple glazed windows." Renewable Energy 150 (2020): 167-175. https://doi.org/10.1016/j.renene.2019.12.115

[46] Miao, Hong, Lingcong Zhang, Sixing Liu, Shanwen Zhang, Saim Memon, and Bi Zhu. "Laser Sealing for Vacuum Plate Glass with PbO-TiO2-SiO2-RxOy Solder." Sustainability 12, no. 8 (2020): 3118.

https://doi.org/10.3390/su12083118

[47] Zhang, Shanwen, Min Kong, Saim Memon, Hong Miao, Yanjun Zhang, and Sixing Liu. "Thermal Analysis of a New Neutron Shielding Vacuum Multiple Glass." Sustainability 12, no. 8 (2020): 3083.

https://doi.org/10.3390/su12083083

[48] Memon, Saim, and Philip C. Eames. "Design and development of lead-free glass-metallic vacuum materials for the construction and thermal performance of smart fusion edge-sealed vacuum glazing." Energy and Buildings (2020): 110430.

https://doi.org/10.1016/j.enbuild.2020.110430

[49] Zhang, Shanwen, Min Kong, Hong Miao, Saim Memon, Yanjun Zhang, and Sixing Liu. "Transient temperature and stress fields on bonding small glass pieces to solder glass by laser welding: Numerical modelling and experimental validation." Solar Energy 209 (2020): 350-362.

https://doi.org/10.1016/j.solener.2020.09.014

[50] Memon, Saim, Farukh Farukh, and Karthikeyan Kandan. "Effect of cavity vacuum pressure diminution on thermal performance of triple vacuum glazing." Applied Sciences 8, no. 9 (2018): 1705.

https://doi.org/10.3390/app8091705

[51] Memon, Saim. "Experimental measurement of hermetic edge seal's thermal conductivity for the thermal transmittance prediction of triple vacuum glazing." Case studies in thermal engineering 10 (2017): 169-178. https://doi.org/10.1016/j.csite.2017.06.002

[52] Memon, Saim, Farukh Farukh, Philip C. Eames, and Vadim V. Silberschmidt. "A new low-temperature hermetic composite edge seal for the fabrication of triple vacuum glazing." Vacuum 120 (2015): 73-82.

https://doi.org/10.1016/j.vacuum.2015.06.024

[53] Memon, Saim. "Thermal Conductivity Measurement of Vacuum Tight Dual-Edge Seal for the Thermal Performance Analysis of Triple Vacuum Glazing." Impact of Thermal Conductivity on Energy Technologies (2018): 133.

http://dx.doi.org/10.5772/intechopen.74255

[54] Memon, Saim. "Design, development and thermal performance analysis of ultra-low heat loss triple vacuum glazing." In Solar World Congress 2017-Innovation for the 100\% renewable energy transformation. Abu Dhabi. (2017) ISBN 978-3-981 465 9-7-6. https://doi.org/10.18086/swc.2017.15.04

[55] Khan, Asif, Saim Memon, and Tariq Pervez Sattar. "Analyzing integrated renewable energy and smart-grid systems to improve voltage quality and harmonic distortion losses at electric-vehicle charging stations." IEEE Access 6 (2018): 26404-26415.

https://doi.ord/10.1109/ACCESS.2018.2830187 
[56] Makeen, Peter, Hani A. Ghali, and Saim Memon. "Experimental and Theoretical Analysis of the Fast Charging Polymer Lithium-Ion Battery Based on Cuckoo Optimization Algorithm (COA)." IEEE Access 8 (2020): 140486140496. https://doi.org/10.1109/ACCESS.2020.3012913

[57] Khan, Asif, Saim Memon, and T. P. Sattar. "Integration and management of solar energy for electric vehicle charging station." In Solar World Congress 2017-Innovation for the 100\% renewable energy transformation. Abu Dhabi, (2017). ISBN 978-3-981 465 9-7-6.

https://doi.org/10.18086/swc.2017.16.03

[58] Memon, Saim. "Advanced Thermoelectric Materials for Energy Harvesting Applications." .IntechOpen Publisher, London, ISBN: 978-1-78984-529-7, (2020).

https://doi.org/10.5772/intechopen.77430

[59] Memon, Saim, and Khawaja Noman Tahir. "Experimental and analytical simulation analyses on the electrical performance of thermoelectric generator modules for direct and concentrated quartz-halogen heat harvesting." Energies 11, no. 12 (2018): 3315.

https://doi.org/10.3390/en11123315

[60] Memon, Saim. "Introductory Chapter: Introduction to Advanced Thermoelectric Materials for Energy Harvesting Applications", Advanced Thermoelectric Materials for Energy Harvesting Applications, IntechOpen, London. (2019). https://doi.org/10.5772/intechopen.89640

[61] Memon, Saim, Maekele Mihreteab, Takao Katsura, Ali Radwan, Shanwen Zhang, Ahmed A. Serageldin, and Essam M. Abo-Zahhad. "Experimental and theoretical performance evaluation of parabolic trough mirror as solar thermal concentrator to thermoelectric generators." International Journal of Solar Thermal Vacuum Engineering 1, no. 1 (2020): 22-38. ISSN online (2716-6953).

https://doi.org/10.37934/stve.1.1.2238

[62] Beatty, Christina, and Stephen Fothergill. "The Seaside Economy: The final report of the seaside towns research project." (2003).

[63] Beaudoin, Greg, Derek Robertson, Ronan Doherty, Dean Corren, Bill Staby, and Laurie Meyer. "Technological challenges to commercial-scale application of marine renewables." Oceanography 23, no. 2 (2010): 32-41. https://www.jstor.org/stable/24860708

[64] Gross, Robert, Matthew Leach, and Ausilio Bauen. "Progress in renewable energy." Environment international 29, no. 1 (2003): 105-122.

https://doi.org/10.1016/S0160-4120(02)00130-7 